\title{
Management of Urinary Stone Disease: Prevention, Treatment and Follow-Up
}

\author{
Mete Özkıdık ${ }^{1 *}$, Tuncer Bahçeci ${ }^{2}$ and Anar Ibrahimov ${ }^{3}$ \\ ${ }^{1}$ Clinic of Urology, Yerköy State Hospital, Turkey \\ ${ }^{2}$ Clinic of Urology, Sanliurfa Research and Training Hospital, Turkey \\ ${ }^{3}$ Department of Urology, Ankara University Faculty of Medicine, Turkey
}

Received: 制: September 19, 2018; Published: 制: October 10, 2018

*Corresponding author: Mete Özkıdık, Yerköy State Hospital, Yerköy, Yozgat, Turkey

Keywords: Composition; Endourology; Stone; Ureter; Urinary

\section{Introduction}

Urinary stone disease is a common affliction of modern society. With westernization of global culture, the incidence of urinary stone disease is increasing worldwide. The prevalence varies on different societies due to the geographical, genetic and dietary factors [1]. In countries with a high standard of life such as Canada, USA or Nordic Societies, urinary stone prevalence is notably high as $>10 \%$ [2]. Male/female predominancy have been decreasing over recent years [3]. In addition, children tend to form urinary stones from earlier ages [3]. All these determinations mentioned above reveal that stone formation is an important public health problem to be seriously concerned.

\section{Risk Groups for Urinary Stone Disease}

The risk for stone formation is of particular interest because of its association with prevention and recurrence. In addition, it is imperative for pharmacological treatment [4]. Approximately $50 \%$ of stone formers experience recurrence of stones once in their remaining lifetime [4]. However, a group of patients are under highrisk of recurrence so they are possible candidates for preventive pharmacological therapies.

\section{High-Risk Stone Formers}

a) Early Onset of Stone Formation.

b) Familial Stone Formation.

c) Solitary Kidney.

d) Hyperparathyroidism.

e) Metabolic Syndrome.

f) Gastrointestinal Malabsorptive Conditions.

g) Neurogenic Bladder.

h) Cystinuria. i) Renal Tubular Acidosis Type 1.

j) Ureteropelvic Junction Obstruction.

k) Vesicoureterorenal Reflux.

l) Horseshoe Kidney.

\section{Classification of Stones}

Urinary stones can be classified due to their composition, aetiology or characteristics on radiography. Stone composition is the basis for further management of patients. Urinary stones often compose of a mixture of different minerals. (Table 1) summarizes the most relevant components. Aetiology is another parameter for classification of urinary stones. It is also important to prevent recurrence in stone formers in their rest of life. (Table 2) lists groups of urinary stones according to their aetiology. Appearance of urinary stones on radiography is associated with their mineral composition. In addition, non-contrast-enhanced computed tomography can be used to determine the density of the stones which would affect treatment decisions (Table 3).

Table 1: Composition of Urinary Stones.

\begin{tabular}{|c|c|}
\hline \multicolumn{2}{|c|}{ Composition of Urinary Stones } \\
\hline Calcium oxalate monohydrate & Whewellite \\
\hline Calcium oxalate dihydrate & Wheddelite \\
\hline Calcium phosphate & Apatite \\
\hline Calcium carbonate & Aragonite \\
\hline Uric acid & Uricite \\
\hline Magnesium ammonium phosphate & Struvite \\
\hline Cystine & - \\
\hline Xanthine & - \\
\hline 2,8-Dihydroxyadenine & - \\
\hline
\end{tabular}


Table 2: Classification of Stones According to Aetiology.

\begin{tabular}{|c|c|c|}
\hline Infection Stones & Non-Infection Stones & Genetic Causes \\
\hline $\begin{array}{c}\text { Magnesium } \\
\text { ammonium phosphate }\end{array}$ & Calcium oxalate & Cystine \\
\hline Carbonate apatite & Calcium phosphate & Xanthine \\
\hline Ammonium urate & Uric acid & 2,8-Dihydroxyadenine \\
\hline
\end{tabular}

Table 3: X-ray Characteristics of Urinary Stones.

\begin{tabular}{|c|c|}
\hline Radiopaque Stones & Radiolucent Stones \\
\hline Calcium oxalate dihydrate & Uric acid \\
\hline Calcium oxalate monohydrate & Xanthine \\
\hline Calcium phosphate & 2,8-Dihydroxyadenine \\
\hline
\end{tabular}

\section{Diagnostic Imaging}

Ultrasound is the primary diagnostic tool with its multiple advantages such as low cost, reproducibility and having no risk of radiation which is very important for renal colic in pregnancy [5]. US has an acceptable sensitivity of $45 \%$ and specificity of $>85 \%$ both for renal and ureteric stones [5]. Appearance of urinary tract dilatation also affects the sensitivity of US particularly for ureteric stones. Kidney-Ureter-Bladder (KUB) radiography is helpful in differentiating between radiopaque and radiolucent stones so that it is commonly used for follow-up rather decisive diagnosis. Although the advantages of US are mentioned above, some patients need emergent evaluation with computed tomography such as cases with solitary kidney or signs of pyelonephritis. Non-contrastenhanced computed tomography has a sensitivity of $100 \%$ and specificity of $>94.9 \%$ for urinary stones $>3 \mathrm{~mm}$ except indinavir stones [6]. In addition, CT gives detailed information about the abdominal pain in the absence of stones [7]. Risk of radiation can be reduced by low-dose CT without significant loss of diagnostic certainty. (96.6\% sensitivity, 94.9\% specificity)[8] Stones which have low density such as uric acid or xanthine stones can be easily detected on CT.

Moreover, dual-energy CT, a relatively new CT modality, can differentiate uric acid stones from calcium containing stones [9]. Imaging also gives valuable information to the physician about urinary anatomy which affects treatment decision. CT gives detailed information about kidney and surrounding structures, diversities such as duplicated collecting systems or ectopic kidneys so that CT is the standard imaging procedure before surgical intervention.

\section{Treatment Modalities for Urinary Stones}

Asymptomatic renal stones could be observed with semiannual follow-up. Treatment should be considered if stone growth or recurrent flank pain is detected.

\section{Spontaneous Passage of Pelvi-Ureteric Stones}

Absolutely not all patients with pelvi-ureteric stones undergo surgical intervention. Proper hydration, non-steroidal antiinflammatuar drugs, $\alpha 1$ adrenergic blockers help spontaneous passage of urinary stones and it is regarded as medical expulsive therapy (MET) [10]. Stones $\leq 4 \mathrm{~mm}$, ureteric stones under the location of iliac bifurcation are more likely to pass spontaneously to the bladder [11]. However, patients with severe renal colic symptoms or pyelonephritis should not be observed with MET because of the risk of septicemia and septic shock.

\section{Oral Chemolysis}

Oral chemolysis is a non-invasive treatment alternative only for uric acid stones. Patients with a prior stone analysis reporting uric acid stone or recurrent stone formers with low urinary $\mathrm{pH}$, also stones with radiolucent X-ray characteristics and low density on CT would be good candidates for oral chemolysis. Oral chemolysis is based on alkalinisation of urine by application of alkaline citrate or sodium bicarbonate. The higher the urinary $\mathrm{pH}$, the more effective the chemolysis. However, it might promote calcium phosphate stone formation. Therefore, urinary $\mathrm{pH}$ should be adjusted to approximately 7.0.

\section{Extracorporeal Shock Wave Lithotripsy}

Enhancements in endourology have caused to decrease interest in ESWL in recent years. Although endourologic interventions have higher stone free rates, ESWL has still advantages over them. Children are good candidates for ESWL, because of its high efficacy and low complication rates [12]. Adults who have multipl or severe co-morbidities constitute high risk groups for surgical intervention so that ESWL is a good alternative particularly for cases with renal, pelvic or proximal ureteric stones $\leq 2 \mathrm{~cm}$.

\section{Ureteroscopy and Retrograde Intrarenal Surgery}

Rigid ureteroscopes are safe and effective for treatment of ureteric stones. Ureteroscopy have been the standard procedure for distal ureteric stones. However, proximal ureteric stones are more likely to be pushed back to the kidney during intervention so that flexibl ureteroscopes are preferred. RIRS by flexibl ureteroscopes is becoming more and more commonly performed in recent years. Shorter days of hospitalization, lower degrees of postoperative pain and lower rates of blood loss are main advantages of RIRS [13] over percutaneous nephrolithotomy. (PNL)

\section{Percutaneous Nephrolithotomy}

Over years, PNL has been performed with standard 24-30 f nephroscopes. With popularization of minimization of surgical instruments, mini PNL have been widely accepted by several authors. First, these miniaturised instruments have been developed for pediatric cases but by the time they have become to replace standard intruments in all cases. According to the recent literature, mini PNL has comparable stone free rates with standard PNL but longer operation times. Perioperative blood loss and need for opioid analgesics are less likely in mini PNL. Another debate over PNL is whether supin or prone is the optimal position for the intervention. Recent literature has indicated similar efficacy and complication rates [14] but with an advantage of supin PNL as opportunity of concomitant RIRS [15].

\section{Conclusion}

Urinary stone disease should be considered as a prominent problem concerning public health. Proper diet and hydration, modification of sedentary lifestyle are basic preventive measures to be concerned even from childhood. In addition, history of urinary 
stone treatment should be regarded as an important risk factor for recurrence. Updates in recent treatment choices, both in medical therapies and surgical interventions, should be followed closely to perform the most proper treatment alternative for each case.

\section{References}

1. Trinchieri A CG (2003) Epidemiology, in Stone Disease. In: Segura JW, Khoury S, Pak CY, Preminger GM, Tolley D (Eds.). Health Publications: Paris.

2. Brändle E, Wilbert D, Köhrmann KU, Alken P (2003) Study on the prevalence and incidence of urolithiasis in Germany comparing the years 1979 vs. 2000. Eur Urol 44: 709.

3. Hesse AT (2009) Urinary Stones, Diagnosis, Treatment and Prevention of Recurrence. (3 ${ }^{\text {rd }}$ Edition). 2009, Basel, Switzerland.

4. Strohmaier WL (2000) Course of calcium stone disease without treatment. What can we expect? Eur Urol 37: 339.

5. Ghiculete D, Pace KT, Honey RJ (2010) Limitations to ultrasound in the detection and measurement of urinary tract calculi. Urology 76: 295.

6. Smith Bindman R, Chandra Aubin, John Bailitz, Rimon N Bengiamin, Carlos A Camargo, et al. (2014) Ultrasonography versus computed tomography for suspected nephrolithiasis. N Engl J Med 371: 1100.

7. Heidenreich A, Desgrandschamps F, Terrier F (2002) Modern approach of diagnosis and management of acute flank pain: review of all imaging modalities. Eur Urol 41: 351.

ISSN: 2574-1241

DOI: $10.26717 / B J S T R .2018 .09 .001862$

Mete Özkıdık. Biomed J Sci \& Tech Res

CC (P) This work is licensed under Creative

Submission Link: https://biomedres.us/submit-manuscript.php
8. Niemann T, Kollman T, Bongartz G (2008) Diagnostic performance of low-dose CT for the detection of urolithiasis: a metaanalysis. AJR Am J Roentgenol 191: 396.

9. Zheng X, Liu Y, Li M, Wang Q, Song B (2016) Dual-energy computed tomography for characterizing urinary calcified calculi and uric acid calculi: A meta-analysis. Eur J Radiol 85: 1843.

10. Pickard R, K Starr, G Maclennan, Thomas Lam, Ruth Thomas, et al. (2015) Medical expulsive therapy in adults with ureteric colic: a multicentre, randomised, placebo-controlled trial. Lancet 386: 341.

11. Furyk JS, Chu K, Banks C, Greenslade J, Keijzers G, et al. (2016) Distal Ureteric Stones and Tamsulosin: A Double-Blind, Placebo-Controlled, Randomized, Multicenter Trial. Ann Emerg Med 67: 86.

12. Rassweiler JJ, Renner C, Chaussy C, Thuroff S (2001) Treatment of renal stones by extracorporeal shockwave lithotripsy: an update. Eur Urol 39: 187.

13. Turna B, Stein RJ, Smaldone MC, Santos BR, Kefer JC, et al. (2008) Safety and efficacy of flexible ureterorenoscopy and holmium: YAG lithotripsy for intrarenal stones in anticoagulated cases. J Urol 179: 1415.

14. Yuan D, Liu Y, Rao H, Cheng T, Sun Z, et al. (2016) Supine Versus Prone Position in Percutaneous Nephrolithotomy for Kidney Calculi: A MetaAnalysis. J Endourol 30: 754.

15. Cracco CM, Scoffone CM (2011) ECIRS (Endoscopic Combined Intrarenal Surgery) in the Galdakao-modified supine Valdivia position: a new life for percutaneous surgery? World J Urol 29: 821.

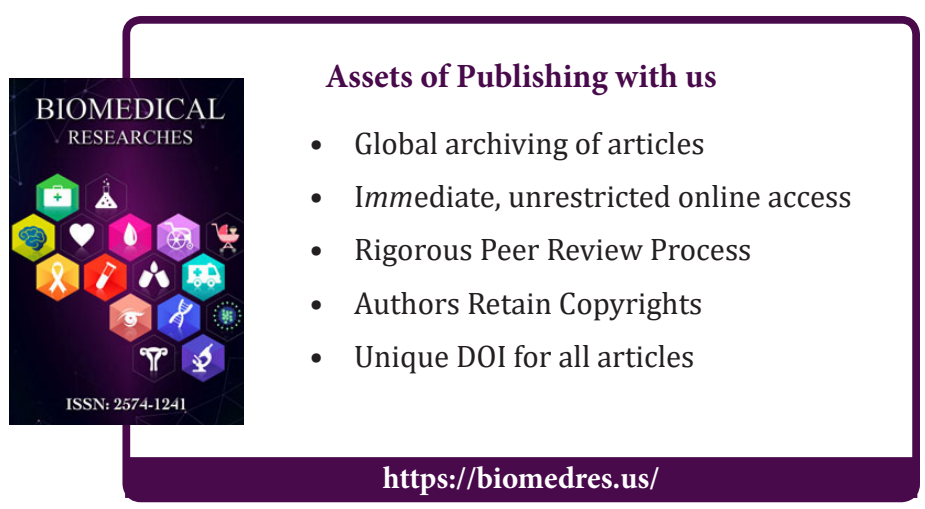

